\title{
Type II 5'Deiodinase Thr92Ala Polymorphism Is Associated with CVD Risk among Type 2 Diabetes Mellitus Patients
}

\author{
Yelakati Dhanunjaya ${ }^{1}$, Pragna Balubai Dolia ${ }^{1,2}$, Rajam Chitraa ${ }^{1}$ \\ ${ }^{1}$ Institute of Biochemistry, Madras Medical College \& GH, Chennai, India \\ ${ }^{2}$ Department of Biochemistry, Madha Medical College \& Hospital, Chennai, India \\ Email: drpragna.mohan@gmail.com
}

Received 31 December 2015; accepted 1 February 2016; published 6 February 2016

Copyright (C) 2016 by authors and Scientific Research Publishing Inc.

This work is licensed under the Creative Commons Attribution International License (CC BY). http://creativecommons.org/licenses/by/4.0/

c) (i) Open Access

\begin{abstract}
Background: The physiological ratio of $T_{3}: T_{4}$ is essential to trigger the biological actions, since the $\mathrm{T}_{3}: \mathrm{T}_{4}$ ratio is efficiently regulated by extrathyroidal selenodeiodinases. Thr92Ala is a common variant in the DIO2 gene, which may have an implication in decreased phenotypic expression, but previous studies had conflicting outcomes. Consequently, we have undertaken this study to understand the effect of this SNP on CVD risk among type 2 diabetics. Methods: We included 130 T2DM patients without signs of CVD as controls and 106 proved CVD patients with T2DM as cases. The entire subjects were genotyped for Thr92Ala of DIO2 gene. FBG, lipid \& thyroid profile, HDL sub-fractionations, type II deiodinase, malondialdehyde, paraoxonase, and superoxide dismutase were measured according to standard procedures. Results: The mean DIO2 levels in Ala/Ala genotypes were significantly lower than $\mathrm{Thr} / \mathrm{Thr}+\mathrm{Thr} /$ Ala genotypes $(122 \pm 39 \mathrm{ng} / \mathrm{ml} \& 161 \pm 32$ $\mathrm{ng} / \mathrm{ml}$ respectively). The thyroid profile was normal in all the subjects; merely it was altered significantly among the Ala/Ala genotypes when compared with Thr/Thr + Thr/Ala genotypes. Remarkably, there is a significant decrease in $\mathrm{T}_{3}: \mathrm{T}_{4}$ and $\mathrm{HDL}_{3}: \mathrm{HDL}_{2}$ ratios and paraoxonase activity among Ala/Ala genotypes when compared with $\mathrm{Thr} / \mathrm{Thr}+\mathrm{Thr} / \mathrm{Ala}$ genotypes. TSH and $\mathrm{T}_{4}$ levels were near to upper normal levels among Ala/Ala genotype. $\mathrm{HDL}_{3}: \mathrm{HDL}_{2}$ ratio is positively correlated with paraoxonase activity among Thr/Thr + Thr/Ala genotypes $(r=0.36, p<0.05)$. Conclusion: Phenotype expression of $\mathrm{DIO} 2$ gene, thyroid profile, $\mathrm{HDL}_{2}: \mathrm{HDL}_{2}$ ratio and paraoxonase activity are altered among the Ala/Ala genotype. Thus, Ala/Ala genotype plays a key role in thyroid dysfunction, dyslipidemia and the development of CVD risk among type 2 diabetics.
\end{abstract}

\section{Keywords}

DI02 Thr92Ala, Thyroid Hormones, DYSLIPIDEMIA, Type 2 Diabetes Mellitus, CVD Risk 


\section{Introduction}

The association of diabetes and thyroid dysfunction has long been known [1]. The pervasiveness of thyroid dysfunction among the diabetics was mainly associated with autoimmune disease, female gender, obesity and insulin resistance. Consequently, a thyroid hormone imbalance may have several detrimental metabolic effects on an individual. The physiological proportion of $\mathrm{T}_{3}: \mathrm{T}_{4}$ is significant to elicit biological actions [2] [3], thus alterations of this ratio would anticipate in thyroid diseases such as hypo and hyperthyroidism [4]. Lipids are one among the several biomolecules directly influenced by thyroid hormones (TH's), thus thyroid dysfunction may contribute to alterations in quantity and quality of lipids, and it is defined as "dyslipidemia". This often occurs in diabetics [5] [6] and it exacerbates with thyroid dysfunction and leads to the development of cardiovascular disease (CVD) risk [7].

For instance, biologically active $3,5,3$ 'triiodothyronine $\left(\mathrm{T}_{3}\right)$ [8] upregulates various enzymes and receptors, which are involved in lipid and lipoprotein metabolism, such as HMG Co-A reductase [9], lecithin cholesterol acyl transferase (LCAT), low-density lipoprotein (LDL) receptor [10], cholesterol ester transfers protein (CETP) [11], and hepatic lipase (HL) [12], etc. Therefore, the decrease in $\mathrm{T}_{3}$ may bring the changes in these proteins.

High-density lipoprotein cholesterol (HDLc) levels were inversely associated with CVD risk; even so, the increase in total HDLc does not truly reduce the risk. Therefore, several prospective studies continue on quality of HDL, known as HDL particle (HDLp) [13]. HDL is a complex heterogeneous molecule which is associated with several freely exchangeable proteins, which include apolipoproteins, lipid transfer proteins, proteins of hemostasis and thrombosis, immune \& complement proteins, growth factors, receptors, and anti-atherogenic proteins [14]. HDL can be divided into sub groups based on its composition, from protein-rich $\mathrm{HDL}_{3}$ to protein poor $\mathrm{HDL}_{1}$. The inter conversion and remodeling of HDL subfractions are dependent on many factors including TH's. Several studies found that the rise in $\mathrm{HDL}_{3}$ is associated with increase in anti-atherogenic function. Nevertheless, the anti-atherogenic property is controversial between $\mathrm{HDL}_{3}$ and $\mathrm{HDL}_{2}$. The formation of $\mathrm{HDL}_{3}$ from $\mathrm{HDL}_{2} \mathrm{was}$ directly influenced by HL, CETP; this phenomenon is called as reverse conversion of HDL [15]. Therefore, a decrease in thyroid function may have a consequence on the HDL metabolism and its quality [16].

The supply of $T_{3}$ from the thyroid gland is very minimal, and the bulk of it is produced from $T_{4}$ by extrathyroidal deiodination [17], which is carried out by three types of selenium dependant monodeiodinases. Type I monodeiodinase (DIO1) and Type II monodeiodinase (DIO2) are imperative, because they remove 5'Iodide from $\mathrm{T}_{4}$ and produce biologically active $\mathrm{T}_{3}$. DIO2 is much more efficient than DIO1, because it has very low $\mathrm{K}_{\mathrm{m}}$ for its preferred substrate $\mathrm{T}_{4}$ [18]. The primary role of DIO2 is to maintain local and intracellular concentration of $T_{3}$ in various tissues such as pituitary, CNS, heart, skeletal muscle and adipose tissue [19]. The half-life of DIO2 is less than 30 min and it is immediately ubiquitinated and degraded in the presence of $\mathrm{T}_{4}$ [18]. Type III mondeiodinase (D3) exclusively deiodinates the inner ring of $T_{4}$ and converts it into reverse $T_{3}\left(\mathrm{rT}_{3}\right)$, which is biologically inactive. Thyroid hormone levels are thus dependent upon the dynamic actions of these three selenoproteins. However, the biochemical properties of selenodeiodinases were well characterized, whereas the effect of genetic factors on their catalytic function was very little, and the results were too controversial [20] [21].

To date, there are several non fatal single nucleotide gene polymorphisms (SNP's) which have been found in DIO genes, and some of them are found to be altered phenotypic expression [21]. Single amino acid changes in the active centre of DIO2 raises $\mathrm{K}_{\mathrm{m}}$ or lowers $\mathrm{V}_{\max }$ and substrate induced loss of DIO2 by ubiquitination [18] [22]. Thr92Ala SNP is a common variant recognized in a DIO2 gene, which is found to be linked to insulin resistance and the decreased phenotypic expression. Moreover, the frequency of this SNP is found to be increased in some ethnic groups, such as Pima Indians and Mexican-Americans, who also have a higher prevalence of insulin resistance [23]. However, the prevalence and effect of this SNP is yet to be studied in large parts of the world.

Therefore, we have proposed that the decrease in circulating $\mathrm{T}_{3}$ is due to altered extrathyroidal deiodination of $\mathrm{T}_{4}$. With this initial idea, we have undertaken this study to understand the effect of Thr92Ala SNP in DIO2 gene on its phenotypic expression, thyroid function, HDL metabolism and role in the development of CVD risk among type 2 diabetes mellitus patients.

\section{Materials \& Methods}

\subsection{Study Population}

In the present study, we included a total of 236 non-smoker and non-alcoholic male subjects who were attending 
diabetic and cardiac OPD of a major South Indian hospital. Among 236 subjects, 130 chronic and uncontrolled type 2 diabetics without signs and symptoms of CVD risk from diabetic OPD were considered as a control group and 106 proved CVD patients (who were recently diagnosed with single or double or triple vessel disease) with type 2 diabetes mellitus from post operative ward of the cardiac department were recruited as a case group. All the subjects were genotyped for Thr92Ala in DIO2 gene and sub grouped accordingly. Informed consent was obtained from all the subjects. The study was approved by the institutional ethics committee.

\subsection{Blood Sampling}

$7 \mathrm{ml}$ fasting blood sample was collected in both clot activator and $\mathrm{K}_{2}$ EDTA Becton Dickinson (BD) vacutainer tubes. Blood sample from post operative cardiac ward patients were collected after 24 hrs of angiogram procedure in order to avoid heparin contamination. Required quantity of whole blood, serum and plasma were separated, aliquoted and stored at $-40^{\circ} \mathrm{C}$ until analysis, this procedure avoids the repeated freezing and thawing effect on measuring parameters.

\subsection{Biochemical Procedures}

Fasting blood glucose (FBG), lipid profile parameters and Apolipoprotein A1 (ApoA1) was estimated by using commercial assay kits (Spinreact, SA, Santa Coloma, Spain). The serum concentration of ApoA1 was obtained after interpolation of observed optical density (OD) values in the Apo calibrator standard graph. Glycosylated haemoglobin $\left(\mathrm{HbA}_{1 \mathrm{C}}\right)$ was estimated in the whole blood by the ion-exchange resin method provided by Diatek, Kolkata. A thyroid profile includes thyroid stimulating hormone (TSH), Total $T_{3}$, Free $T_{3}$, Total $T_{4}$ and Free $T_{4}$, these were measured by using commercial enzyme linked immunosorbent assay (ELISA) kits (BeneSphera ${ }^{\mathrm{TM}}$ / Avantor Performance Materials Ltd., USA). The serum level of $\mathrm{HDL}_{2}$, $\mathrm{HDL}_{3}$ and Type II 5 'monodeiodinase (DIO2) was measured by commercially available ELISA kits (Qayee-Bio, Shanghai, China).

\subsubsection{Basal Paraoxonase (bPON) Activity}

The basal aryl esterase activity of paraoxonase (E.C.3.1.1.2) was measured spectrophotometrically as described previously [24]. PON activity was calculated by using a molar extinction coefficient of $17,000 \mathrm{M}^{-1} \cdot \mathrm{cm}^{-1}$. PON activity expressed as $\mathrm{nmol} \mathrm{PON} / \mathrm{min} / \mathrm{ml}$ of serum.

\subsubsection{Malondialdehyde (MDA)}

Thiobarbituric acid reactive substances (TBARS) as a measure of lipid peroxide (malondialdehyde) were measured spectrophotometrically by using the method described by Draper and Hadley (1990) [25]. Concentration of plasma MDA was expressed in $\mu \mathrm{mol} / \mathrm{L}$.

\subsubsection{Super Oxide Dismutase (SOD) Activity}

SOD activity was determined by the method of Marklund and Marklund (1974) [26]. The activity of SOD expressed in IU/ml.

\subsection{Molecular Methods}

\subsubsection{Materials}

DNA purification kit (PureFast ${ }^{\circledR}$ Blood Genomic DNA purification kit), PCR Master Mix, Agarose gel electrophoresis consumables and primers purchased from HELINI Biomolecules, Chennai, India.

\subsubsection{Primers}

Primers for "A" allele:

FW: ATTGCCACTGTTGTCACCTCCTTCGGT

Rv: CTATGTTGGCGTTATTGTCCATGCGGTC

Primers for " $G$ " allele:

FW: AATTCCAGTGTGGTGCATGTCTCCATTG

Rv: TTTTGGGCCATTCTTTACATTACCTGCCA 


\subsubsection{Thr92Ala (c. 274A > G; p. T92A; rs225014) Genotype Analysis}

Method: Tetra Primer amplification refractory mutation system PCR (TP-ARMS PCR) method as described previously [27].

\section{PCR Procedure:}

Each PCR reaction was carried out in a total volume of $30 \mu \mathrm{L}$, containing $2 \mu \mathrm{L}$ of template DNA, $2 \mu \mathrm{L}$ of primer mix (5 pmoles $/ \mu \mathrm{L}$ ), $20 \mu \mathrm{L}$ master mix and $6 \mu \mathrm{L}$ of water (nuclease free). The solution was overlaid with $5 \mu \mathrm{L}$ of liquid paraffin and incubated for $3 \mathrm{~min}$ at $95^{\circ} \mathrm{C}$, followed by 30 cycles of $30 \mathrm{Sec}$ denaturation $\left(95^{\circ} \mathrm{C}\right), 30$ Sec annealing $\left(60^{\circ} \mathrm{C}\right)$ and $30 \mathrm{Sec}$ extension $\left(72^{\circ} \mathrm{C}\right)$ and an additional 5 minute extension at $72^{\circ} \mathrm{C}$ at the end of the 30 cycles.

A $30 \mu \mathrm{L}$ aliquot of the PCR products was mixed with $8 \mu \mathrm{l} 6 \times$ Gel loading dye and subjected to apply in 2\% agarose gel (in $1 \times \mathrm{TAE}$ buffer). Run electrophoresis at $50 \mathrm{~V}$ until the dye reaches three fourth distance and observe the bands in UV Transilluminator (Figure 1).

- Product size for "A" allele: 276 bp.

- Product size for "G" allele: 418 bp.

- Product size of two outer primers: 639 bp.

\section{Statistical Analysis}

Mean \pm 2 SD were used to describe various parameters in the study groups. One-way analysis of variance (ANOVA) was used to compare the mean difference between study groups. Karl Pearson correlation was used to determine the trend between various parameters within the groups. A linear regression analysis was performed between selected independent and dependent variables within the groups. A two-tailed t-test of $\mathrm{p}<0.05$ was considered as statistically significant. $\chi^{2}$ test of $p>0.05$ was considered for allelic frequency in consistence with Hardy Weinberg Equilibrium (HWE). All the statistical parameters were analyzed by using PASW version 18.0 (SPSS, Chicago, IL) and STATISTICA 7.0 (StatSoft Inc., USA) software packages wherever applicable.

\section{Results}

Genotype and allelic frequency of the study groups were shown in Table 1. Allelic frequency in the control group for Thr92Ala was consistent with HWE $(p=0.46)$, whereas it is not in the case group $(p=0.006)$. Allelic frequency is not significant between the groups. Table 2 shows the various biochemical characteristics in both the study groups. Thr/Thr and Thr/Ala genotypes showing similarities in biochemical characteristics, hence, we considered "recessive inheritance model" to analyze various statistical parameters between and within the $\mathrm{Thr} / \mathrm{Thr}+\mathrm{Thr} / \mathrm{Ala}$ and Ala/Ala genotypes. Ala/Ala genotype has a substantial alteration in base line biochemical parameters when compared with Thr/Thr + Thr/Ala genotypes (Table 2, ANOVA).

The mean \pm SD values of serum DIO2, thyroid profile parameters, $\mathrm{HDL}_{3}: \mathrm{HDL}_{2}$ ratio and basal PON activity were significantly differed between $\mathrm{Thr} / \mathrm{Thr}+\mathrm{Thr} / \mathrm{Ala}$ and Ala/ala genotypes (Table 2). Pearson correlation (r) was performed between selected variables within the Thr/Thr + Thr/Ala and Ala/Ala genotypes (Table 3, Figures 2(a)-(n)). Serum TSH levels were significantly negatively correlated with DIO2 levels in both the Thr/Thr

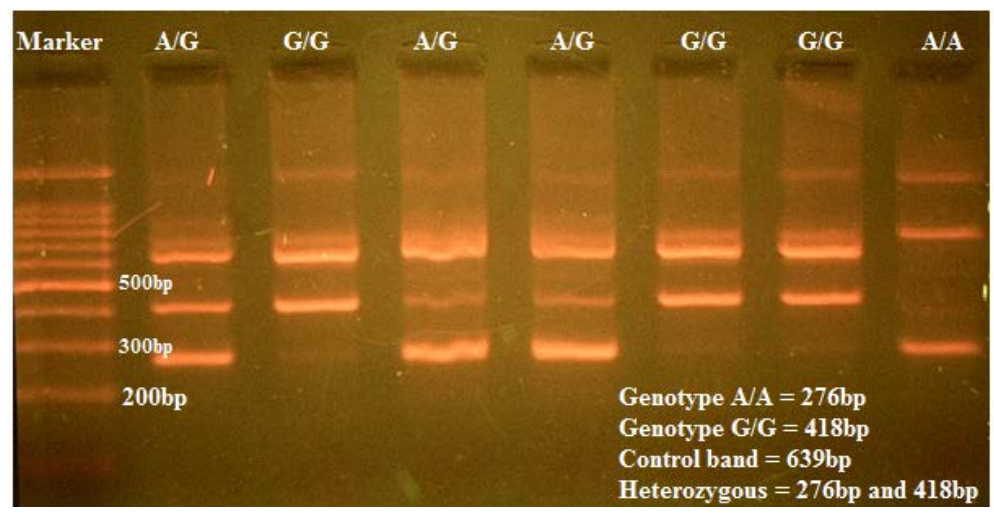

Figure 1. Showing agarose gel electrophoresis of DIO2 Thr92Ala SNP genotypes by TP-ARMS-PCR. 
Table 1. Showing genotype \& allelic frequency for Thr92Ala SNP of DIO2 gene among the study groups.

\begin{tabular}{|c|c|c|c|c|c|}
\hline \multirow{2}{*}{ Subjects } & \multicolumn{3}{|c|}{ Genotype Frequencies (n \& \%) } & \multirow{2}{*}{ Allele Frequencies (\%) } & \multirow{2}{*}{ P (HWE) } \\
\hline & Thr/Thr & Thr/Ala & Ala/Ala & & \\
\hline $\begin{array}{l}\text { Controls } \\
(n=130)\end{array}$ & 22 (16.9\%) & $58(44.6 \%)$ & 50 (38.5\%) & $\begin{array}{l}\text { Thr }-39 \% \\
\text { Ala }-61 \%\end{array}$ & $0.46^{*}$ \\
\hline $\begin{array}{c}\text { Cases } \\
(\mathrm{n}=106)\end{array}$ & $11(10.4 \%)$ & $65(58.5 \%)$ & $30(28.3 \%)$ & $\begin{array}{l}\text { Thr }-41 \% \\
\text { Ala }-59 \%\end{array}$ & 0.006 \\
\hline
\end{tabular}

*indicates the allelic frequency consistent with HWE.

Table 2. Showing Mean \pm SD (95\% CI) and one-way ANOVA of various parameters among different groups.

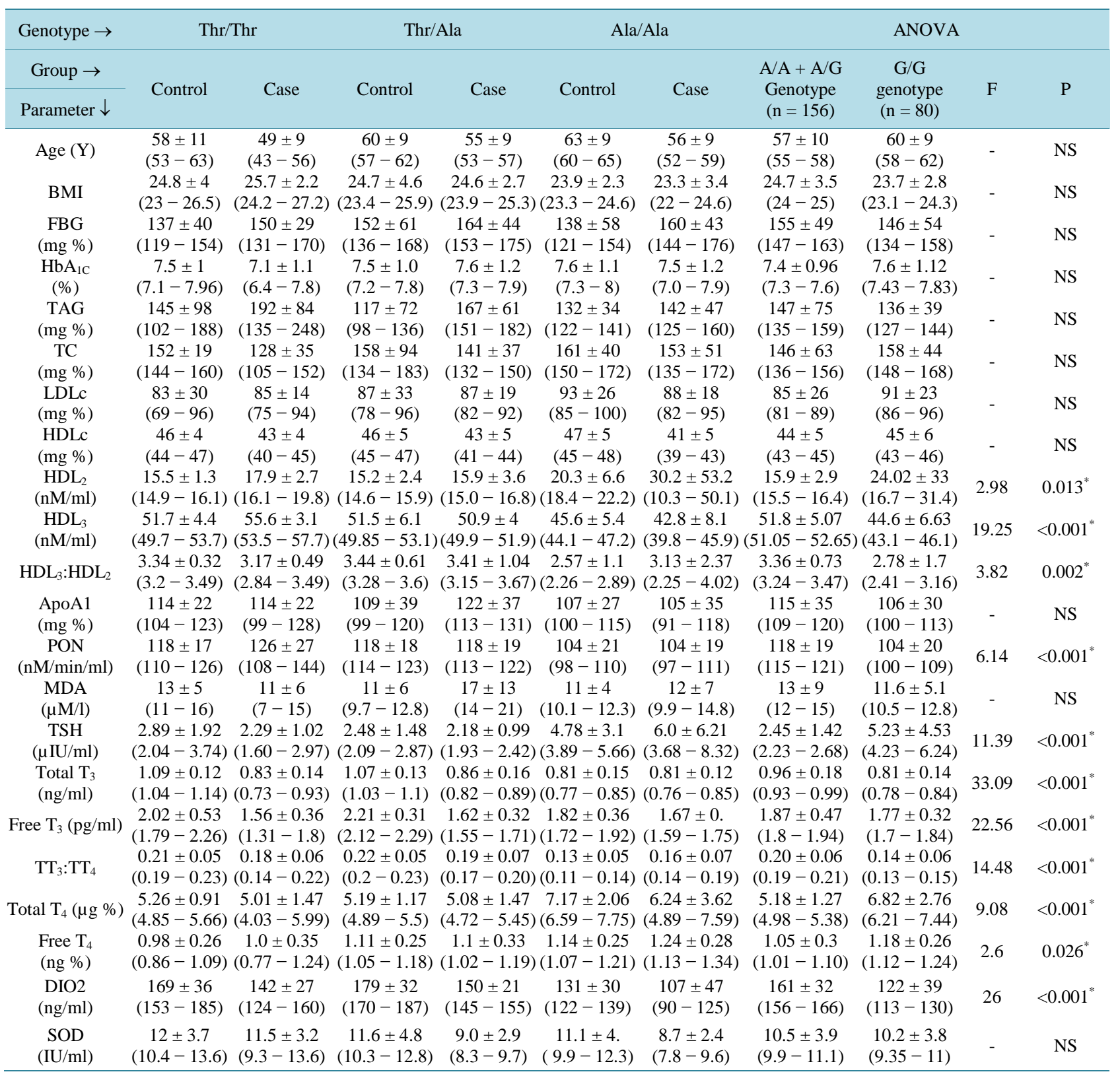

$\left(^{*}\right)$ indicates the statistically significant; ANOVA: analysis of variance; NS: not significant. 
Table 3. Showing Pearson correlation (r) between selected parameters among the genotypes.

\begin{tabular}{|c|c|c|}
\hline Correlation (r) & Thr $/$ Thr + Thr/Ala $(n=156)$ & Ala/Ala $(n=80)$ \\
\hline DIO2 vs. TSH & $-0.37^{*}$ & $-0.38^{*}$ \\
\hline DIO2 vs. $\mathrm{T}_{3}: \mathrm{T}_{4}$ & $0.55^{*}$ & $-0.35^{*}$ \\
\hline TSH vs. $T_{3}: T_{4}$ & -0.11 & 0.015 \\
\hline $\mathrm{T}_{3}: \mathrm{T}_{4}$ vs. $\mathrm{HDL}_{3}: \mathrm{HDL}_{2}$ & $0.33^{*}$ & -0.16 \\
\hline $\mathrm{HDL}_{3}: \mathrm{HDL}_{2}$ vs. PON & $0.36^{*}$ & 0.20 \\
\hline FBG vs. MDA & $0.48^{*}$ & $0.30^{*}$ \\
\hline PON vs. MDA & $-0.25^{*}$ & $-0.23^{*}$ \\
\hline PON vs. SOD & $0.21^{*}$ & $0.29^{*}$ \\
\hline PON vs. ApoA1 & $0.26^{*}$ & $0.27^{*}$ \\
\hline
\end{tabular}

( ) indicates $\mathrm{p}<0.05$.

+ Thr/Ala and Ala/Ala genotypes $(r=-0.36 \&-0.38, p<0.05$, respectively, Table 3, Figure 2(a) \& Figure 2(h)). The proportion of $\mathrm{T}_{3}: \mathrm{T}_{4}$ was significantly positively correlated with DIO2 levels among $\mathrm{Thr} / \mathrm{Thr}+$ Thr/Ala genotypes $(r=0.55, \mathrm{p}<0.05$, Figure 2(b)), whereas this relation was significantly negative in Ala/Ala genotypes ( $r=-0.35, p<0.05$, Figure 2(i)). Moreover, the proportion of $T_{3}: T_{4}$ was positively correlated with $\mathrm{HDL}_{3}: \mathrm{HDL}_{2}$ ratio among Thr/Thr $+\mathrm{Thr} /$ Ala genotypes $(r=0.33, \mathrm{p}<0.05$, Figure 2(d)), whereas it was found to be negative in Ala/Ala genotypes $(r=-0.16$, Figure $2(k))$, but it was not statistically significant. The association between $\mathrm{HDL}_{3}: \mathrm{HDL}_{2}$ ratio and basal PON activity was significantly positive among $\mathrm{Thr} / \mathrm{Thr}+\mathrm{Thr} / \mathrm{Ala}$ genotypes $(r=0.36, p<0.05$, Figure 2(f)), but this association was not significant among Ala/Ala genotypes $(r=$ 0.20 , Figure $2(\mathrm{~m})$ ). Plasma MDA levels were significantly positively correlated with FBG in all the genotypes $(r=0.48$ in Thr/Thr + Thr/Ala; $r=0.30$ in Ala/Ala, Table 3), but the same was negatively correlated with PON activity $(r=-0.25$ for Thr/Thr + Thr/Ala genotypes; $r=-0.23$ for Ala/Ala genotype, Figure 2(g) \& Figure 2(n)). Moreover, basal PON activity was significantly positively correlated with SOD activity $(\mathrm{r}=0.21$ in $\mathrm{Thr} / \mathrm{Thr}+$ Thr/Ala genotypes; $\mathrm{r}=0.29$ in Ala/Ala genotype, $\mathrm{p}<0.05$, Table 3$)$ and ApoA1 levels $(r=0.26$ in Thr/Thr + Thr/Ala genotypes; $r=0.27$ in Ala/Ala genotype, $p<0.05$, Table 3 ) in all the study groups.

Table 4 shows linear regression analysis between selected dependent and independent variables within the $\mathrm{Thr} / \mathrm{Thr}+\mathrm{Thr} / \mathrm{Ala}$ and Ala/Ala genotypes. Among the thyroid profile parameters, $\mathrm{T}_{3}: \mathrm{T}_{4}$ ratio has the best regression line when DIO2 considered as an independent variable $\left(\mathrm{R}^{2}=0.294\right.$, Figure 2(b) \& Figure 2(i)) compared to TSH $\left(\mathrm{R}^{2}=0.127\right.$, Figure 2(a) \& Figure 2(h)) and $\mathrm{fT}_{3}: \mathrm{fT}_{4}$ ratio $\left(\mathrm{R}^{2}=0.10\right.$, Figure 2(c) \& Figure 2(j)). We also performed a linear regression analysis between $\mathrm{T}_{3}: \mathrm{T}_{4}$ ratio, $\mathrm{fT}_{3}: \mathrm{fT}_{4}$ and $\mathrm{HDL}_{3}: \mathrm{HDL}_{2}$. We found a best fit regression equation line between $\mathrm{T}_{3}: \mathrm{T}_{4}$ and $\mathrm{HDL}_{3}: \mathrm{HDL}_{2}$ ratios among $\mathrm{Thr}+\mathrm{Thr} / \mathrm{Thr} / \mathrm{Ala}$ genotypes $\left(\mathrm{R}^{2}=\right.$ 0.11, Figure 2(d)), but this did not occur in Ala/Ala genotypes (Figure 2(k)). We also extended linear regression analysis for $\mathrm{HDL}_{3}: \mathrm{HDL}_{2}$ ratio, $\mathrm{PON}$ and MDA. Basal PON activity is positively regressed on $\mathrm{HDL}_{3}: \mathrm{HDL}_{2}$ ratio $\left(R^{2}=0.133\right.$, Figure $\left.2(f)\right)$, and MDA levels $\left(R^{2}=0.082\right.$, Figure $\left.2(g)\right)$ were negatively regressed on PON activity among $\mathrm{Thr} / \mathrm{Thr}+\mathrm{Thr} /$ Ala genotypes.

\section{Discussion}

The dyslipidemia is a major and common complication in both the endocrinopathies namely diabetes and thyroid dysfunction. Hence, thyroid dysfunction along with diabetes mellitus exacerbates the existing dyslipidemia and quickens the morbidity and mortality from CVD [28]. The biochemical studies on the development of dyslipidemia were well established among the diabetic population [29], whereas on that point, there is a paucity of genetic associated studies. DIO2 Thr92Ala is a common variant found to be related to insulin resistance [20], osteoarthritis [30], hypertension [31], Grave's disease [32], and intelligence quotient alterations associated with iodine deficiency [33]. In the study of Canani et al. found that, the activity of DIO2 in skeletal and thyroid tissues of Ala/Ala genotypes was half of that found in the subjects with Thr/Thr or Thr/Ala genotypes [21]. In the present study the serum DIO2 levels were significantly decreased in Ala/Ala genotypes when compared with 

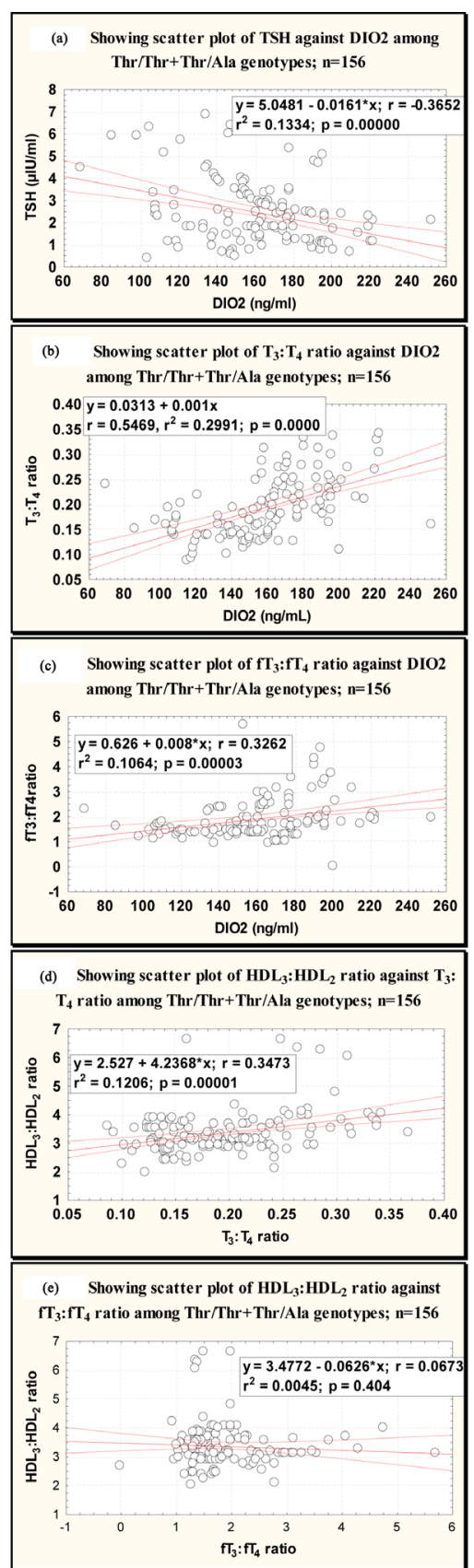
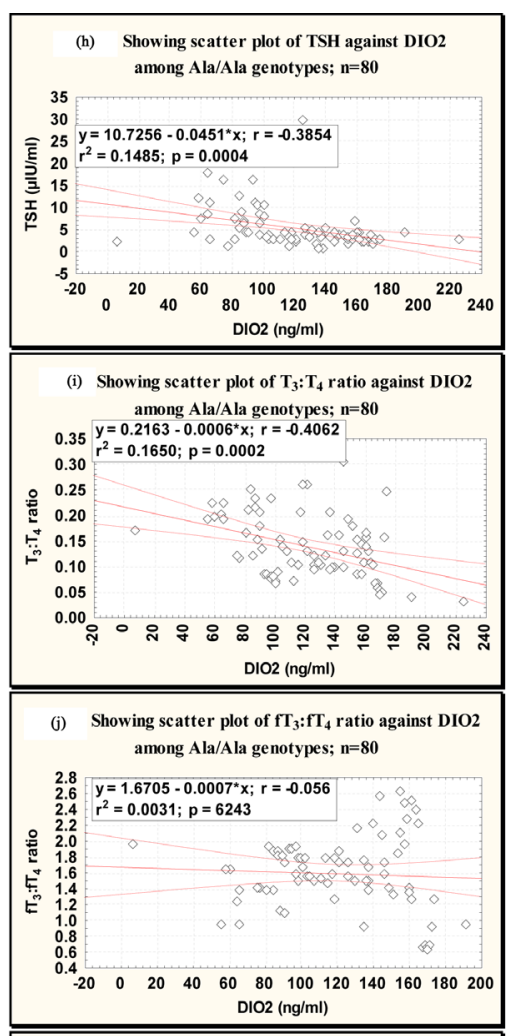

(k) Showing scatter plot of $\mathrm{HDL}_{3}: \mathrm{HDL}_{2}$ ratio against $\mathrm{T}_{3}: \mathrm{T}_{\mathbf{4}}$ ratio among $\mathrm{Ala} / \mathrm{Ala}$ genotypes; $\mathbf{n}=\mathbf{8 0}$
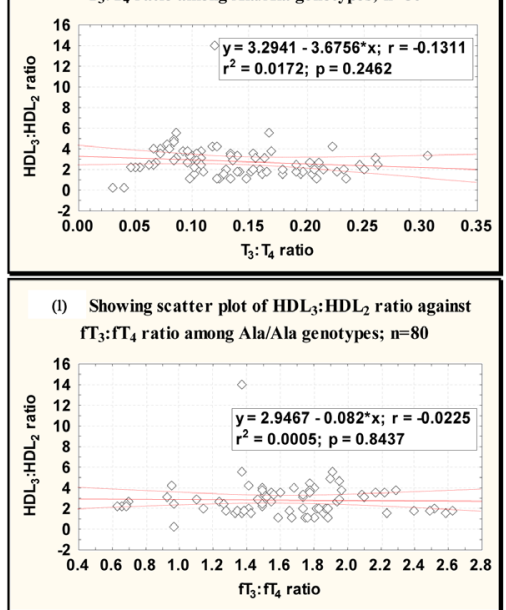
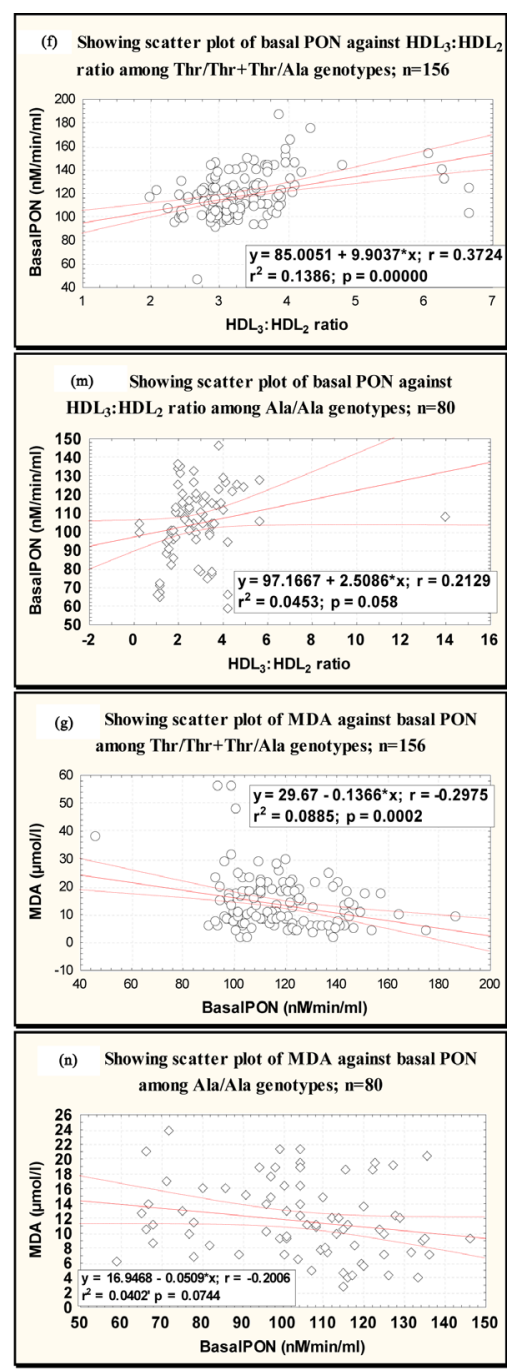

Figure 2. (a)-(n). Showing scatter plots for different parameters among Thr/Thr + Thr//Ala and Ala/Ala genotypes.

Thr/Thr + Thr/Ala genotypes (122 \pm 39 vs. $161 \pm 32$ ng/ml; p < 0.001, Table 2, Figure 3). Our results were concurred with previous studies [21].

Intriguingly, DIO2 levels showed significant correlation with thyroid profile parameters among the study groups. In the present study, thyroid profile among Ala/Ala genotypes were significantly deviated from $\mathrm{Thr} / \mathrm{Thr}$ + Thr/Ala genotypes, although their thyroid profile was in a normal range (Table 2, Figure 3). Total $\mathrm{T}_{3}$ and $\mathrm{fT}_{3}$ levels were near the lower limit of the reference range $(0.81 \pm 0.14 \mathrm{ng} / \mathrm{ml} \& 1.77 \pm 0.32 \mathrm{pg} / \mathrm{ml}$, respectively, Table $2 \&$ Figure 3), whereas TSH and total $\mathrm{T}_{4}$ levels were close to an upper limit of reference range among the Ala/Ala genotypes $(5.23 \pm 4.53 \mu \mathrm{IU} / \mathrm{ml} \& 6.82 \pm 2.76 \mu \mathrm{g} / \mathrm{dl}$ respectively, Table 2 \& Figure 3$)$. This phenomenon ultimately leads to the decrease in $\mathrm{T}_{3}: \mathrm{T}_{4}$ ratio among Ala/Ala genotype.

The half-life of DIO2 is less than a half an hour, whereas it is higher in DIO1. The activity and concentration 
Table 4. Showing simple linear regression analysis between selected independent and dependent variables among Thr/Thr + Thr/Ala and Ala/Ala genotypes.

\begin{tabular}{|c|c|c|c|c|c|c|c|c|c|c|c|c|c|}
\hline \multirow{2}{*}{ Constant } & \multirow{2}{*}{ D.V } & \multicolumn{2}{|l|}{$\mathrm{R}^{2}$} & \multicolumn{2}{|c|}{ Adjusted $\mathrm{R}^{2}$} & \multicolumn{2}{|l|}{ SEE } & \multicolumn{2}{|c|}{ Beta } & \multicolumn{2}{|l|}{ F } & \multicolumn{2}{|l|}{$\mathrm{P}$} \\
\hline & & $\mathrm{A} / \mathrm{A}+\mathrm{A} / \mathrm{G}$ & G/G & $\mathrm{A} / \mathrm{A}+\mathrm{A} / \mathrm{G}$ & $\mathrm{G} / \mathrm{G}$ & $\mathrm{A} / \mathrm{A}+\mathrm{A} / \mathrm{G}$ & $\mathrm{G} / \mathrm{G}$ & $\mathrm{A} / \mathrm{A}+\mathrm{A} / \mathrm{G}$ & $\mathrm{G} / \mathrm{G}$ & $\mathrm{A} / \mathrm{A}+\mathrm{A} / \mathrm{G}$ & $\mathrm{G} / \mathrm{G}$ & $\mathrm{A} / \mathrm{A}+\mathrm{A} / \mathrm{G}$ & $\mathrm{G} / \mathrm{G}$ \\
\hline \multirow{3}{*}{$\mathrm{DIO} 2$} & TSH & 0.133 & 0.148 & 0.127 & 0.137 & 1.32 & 4.2 & $-0.37^{*}$ & $-0.39^{*}$ & 23.7 & 13.6 & $<0.0001$ & $<0.0001$ \\
\hline & $\mathrm{T}_{3}: \mathrm{T}_{4}$ & 0.299 & 0.165 & 0.294 & 0.154 & 0.05 & 0.055 & $0.547^{*}$ & $-0.41^{*}$ & 65.7 & 15.41 & $<0.0001$ & $<0.001$ \\
\hline & $\mathrm{fT}_{3}: \mathrm{fT}_{4}$ & 0.106 & 0.003 & 0.10 & -0.009 & 0.75 & 0.464 & $0.326^{*}$ & -0.06 & 18.34 & 0.24 & $<0.0001$ & 0.62 \\
\hline $\mathrm{T}_{3}: \mathrm{T}_{4}$ & \multirow[b]{2}{*}{$\mathrm{HDL}_{3}: \mathrm{HDL}_{2}$} & 0.12 & 0.017 & 0.11 & 0.004 & 0.69 & 1.69 & $0.35^{*}$ & -0.13 & 21.12 & 1.36 & $<0.0001$ & 0.24 \\
\hline $\mathrm{fT}_{3}: \mathrm{fT}_{4}$ & & 0.004 & 0.0005 & -0.002 & -0.012 & 0.733 & 1.69 & -0.07 & -0.02 & 0.7 & 0.039 & 0.4 & 0.84 \\
\hline $\mathrm{HDL}_{3}: \mathrm{HDL}_{2}$ & PON & 0.138 & 0.045 & 0.133 & 0.033 & 18.15 & 19.68 & $0.372^{*}$ & 0.213 & 24.78 & 3.7 & $<0.0001$ & 0.058 \\
\hline PON & MDA & 0.088 & 0.04 & 0.082 & 0.028 & 8.6 & 5.006 & $-0.30^{*}$ & -0.20 & 14.85 & 3.27 & $<0.001$ & 0.074 \\
\hline
\end{tabular}

*indicates significant of beta at $\mathrm{p}<0.05$. D.V: dependent variable; $\mathrm{R}^{2}$ : coefficient of determination; SEE: Standard Error of Estimate; F: Fisher's ratio of ANOVA.

of circulating DIO2 levels were finely controlled by its preferred substrate T4, since its' ubiquitination is enhanced by it; this indicates the lower levels of DIO2 among the Ala/Ala variants [18]. In the present study, serum DIO2 levels were significantly negatively correlated with total $\mathrm{T}_{4}$ levels among the Ala/Ala genotypes, which confirms the effect of $\mathrm{T}_{4}$ on the levels of DIO2 (Figure 2(i)). Pituitary DIO2 activity is indispensable for the negative feedback regulation of hypophyseal TSH secretion by circulating $T_{4}$. Thus, a subtle change in $T_{3}: T_{4}$ ratio may have a profound effect on hypothalamus pituitary thyroid (HPT) axis and vice versa. Experiments on DIO2 knockout mice show that, there is an impaired feedback regulation on HPT axis and elevated levels of $\mathrm{T}_{4}$ and TSH with normally circulating $\mathrm{T}_{3}$ [34]. In our study, serum TSH \& $\mathrm{T}_{3}: \mathrm{T}_{4}$ ratio were negatively regressed on DIO2 among the Ala/Ala genotypes $\left(r=-0.39 \& R^{2}=0.137 ; r=-0.41 \& R^{2}=0.154\right.$, Table 4, Figure 2(h) \& Figure 2(i) respectively). In the study of Olga Gumieniak et al., Ala homozygous found to be hypertensive and having higher normal levels of TSH [31]. Thus, Ala/Ala variant has a profound outcome on the phenotypic expression of DIO2 and thyroid function.

Anti-atherogenic properties of HDL are solely dependent on its composition and interaction with various proteins. In the study of Camont et al. was found that, the oxidation of LDL was reduced when the serum samples were incubated with ApoA1, LCAT and PON in the presence or absence of HDL [35]. Therefore, HDL associated proteins play a key role in its anti-atherogenic functions. The inter conversion and remodelling of HDL is dependent on the activity of lipoprotein lipase, hepatic lipase and CETP, etc., which in turn were regulated by $\mathrm{T}_{3}$. Therefore, the physiological concentration of circulating $\mathrm{T}_{3}$ is very important in the metabolism of anti-atherogenic lipoprotein, such as HDL. In our study, $\mathrm{T}_{3}: \mathrm{T}_{4}$ ratio was significantly positively correlated with $\mathrm{HDL}_{3}$ : $\mathrm{HDL}_{2}$ ratio among the Thr/Thr $+\mathrm{Thr} /$ Ala genotypes $(\mathrm{r}=0.33, \mathrm{p}<0.05$, Figure $2(\mathrm{~d}))$, whereas this was negative in Ala/Ala genotypes $(r=-0.13$, Figure $2(\mathbf{k})$ ). Total HDLc levels were not significantly differed among the groups, but the $\mathrm{HDL}_{3}: \mathrm{HDL}_{2}$ ratio significantly decreased in Ala/Ala genotypes (2.78 \pm 1.7 vs. $3.36 \pm 0.73$, Table 2). The total HDLc is normally rising in subclinical hypothyroidism patients; which is due to the rise in $\mathrm{HDL}_{2}$ fraction [36]. In the present study, we found significant positive correlation between paraoxonase activity and $\mathrm{HDL}_{3}$ levels among the Thr/Thr + Thr/Ala genotypes ( $\mathrm{r}=0.38$, Figure 2(f)) when compared with Ala/Ala genotype $(r=20$, Figure $2(m))$. From the study results, it is clear that the physiological proportion of $T_{3}: T_{4}$ is important in the metabolism and remodeling of HDL particle. We also measured serum levels of ApoA1, which was not significantly differed between genotypes, but its' associated protein, namely paraoxonase was significantly altered (Table 2).

The DIO2 catalyzed pituitary $\mathrm{T}_{3}$ is very important for regulation of HPT axis, whereas skeletal muscle $\mathrm{T}_{3}$ is important for up regulation of insulin-dependent GLUT4 [37]. In the study of Mentuccia et al. found that, the novel Ala/Ala variant was associated with a $20 \%$ decreased glucose disposal rate and higher body mass index (BMI) [23]. Therefore, it is thought that thyroid dysfunction may cause the low glucose disposal rate in diabetics with Ala/Ala genotype. From the study results, we propose that, there is a doubling of both hyperglycemia and dyslipidemia among the Ala/Ala genotypes. Moreover, hyperglycemia induces the production of reactive oxy- 
gen species (ROS) through the auto oxidation of glucose. These ROS irreversibly damage several bio molecules, which include lipoproteins and convert them to lipid peroxides. The well-known lipid peroxide end product is malondialdehyde (MDA), which is irreversibly bound to several bio molecules and damages them.

In the present study, all the subjects were found to be of poor glycemic status (FBG $=150 \pm 51 \mathrm{mg} / \mathrm{dl}$ ) which were positively correlated with MDA levels $(r=48$ in Thr/Thr + Thr/Ala genotypes $\& r=30$ in Ala/Ala genotypes, Table 3). On the other hand, plasma levels of MDA were significantly negatively correlated with PON activity ( $r=-0.25 \& r=-0.23$, Table 3, Figure 2(g) \& Figure 2(n)). Moreover, PON activity is mostly associated with a high $\mathrm{HDL}_{3}: \mathrm{HDL}_{2}$ ratio among the $\mathrm{Thr} / \mathrm{Thr}+\mathrm{Thr} /$ Ala genotypes; this indicates that $\mathrm{HDL}_{3}$ fraction of total HDL is playing a key role in anti-atherogenic function than $\mathrm{HDL}_{2}$. In the present study, we also measured the activity of SOD in all subjects and we did not find any significant difference between the groups (Table 3). However, the SOD activity positively correlated with BPON activity (Table 3) and negatively correlated with both FBG and MDA levels in all the subjects. The similar results were shown in our previous study [13].

Therefore, we propose that, Ala/Ala genotype with lower DIO2 levels would decrease relative concentration of $T_{3}$ in situ could create a state of intracellular hypothyroidism, decreasing the expression of genes involved in energy, lipid metabolism and exacerbating the diabetic complications and leading to CVD risk.

However, our study has certain limitations, which include: 1 ) the small sample size due to difficulty in recruiting volunteer subjects, therefore it requires a large sample prospective study to support and strengthen our results, 2) we could not find any genetic wide association studies (GWAS) for this SNP to compare our results, and 3) the lack of funding resources.

\section{Conclusion}

In conclusion, to the best of our knowledge, this is the first study intended to understand the association of DIO2 Thr92Ala SNP on thyroid function and the development of CVD risk among the South Indian type 2 diabetics. Our results show that the DIO2 Ala92Ala genotype is associated with altered levels of DIO2 and thyroid profile parameters when compared with Thr/Thr + Thr/Ala genotypes. Moreover, an altered thyroid hormone level among the Ala/Ala genotype was also associated with decreased levels of $\mathrm{HDL}_{3}: \mathrm{HDL}_{2}$ ratio and paraoxonase activity. Our results further indicate that there is a development of thyroid dysfunction among Ala/Ala genotypes, which resembles like an "intrinsic thyroid disease".

\section{Conflict of Interest}

The authors have declared that there is no any kind of conflict of interest for this study.

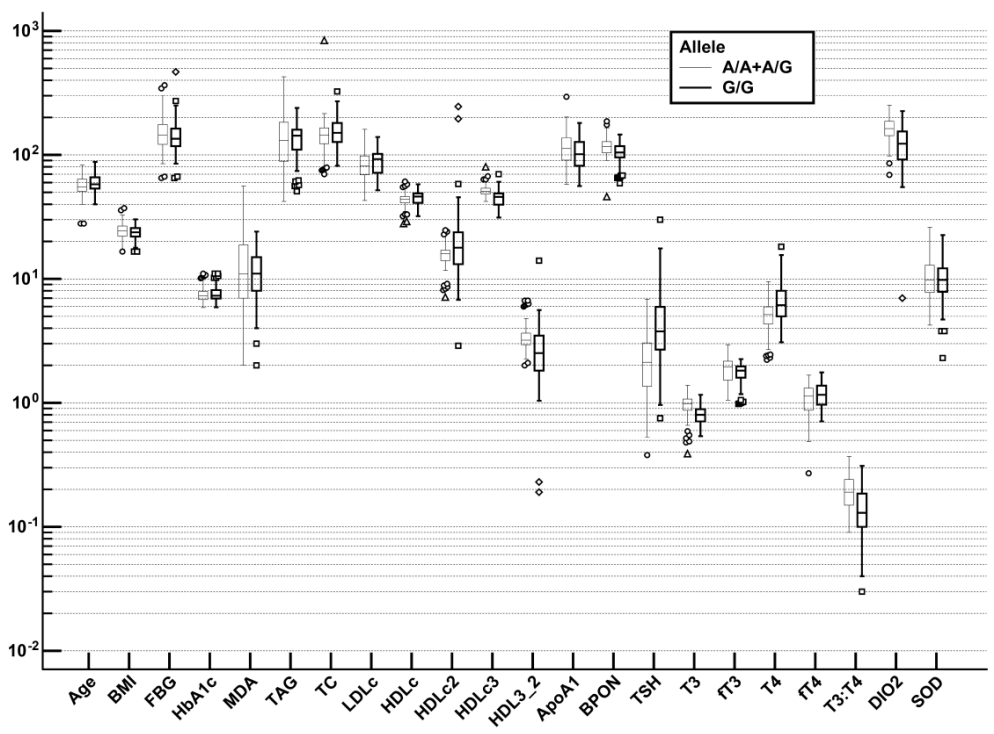

Figure 3. Showing box \& whisker plot for all the parameters among Thr/Thr + Thr/Ala and Ala/Ala genotypes. 


\section{Funding}

Nil.

\section{Acknowledgements}

The authors have acknowledged the staff of Diabetology and Cardiology for their support.

\section{References}

[1] Feely, J. and Isles, T.E. (1979) Screening for Thyroid Dysfunction in Diabetics. British Medical Journal, $2,1439$. http://dx.doi.org/10.1136/bmj.2.6202.1439-b

[2] Larsen, P.R. and Frumess, R.D. (1977) Comparison of the Biological Effects of Thyroxin and Triiodothyronine in the Rat. Endocrinology, 100, 980-988. http://dx.doi.org/10.1210/endo-100-4-980

[3] Braverman, L.E. and Utiger, R.D. (1996) Werner and Ingbarís. The Thyroid (A Fundamental and Clinical Text). Lippincott-Raven Publishers, Philadelphia and New York.

[4] Larsen, P.R. (1975) Thyroidal Triiodothyronine and Thyroxine in Graves' Disease: Correlation with Presurgical Treatment, Thyroid Status, and Iodine Content. The Journal of Clinical Endocrinology \& Metabolism, 41, 1098-1104. http://dx.doi.org/10.1210/jcem-41-6-1098

[5] Loeb, J.N. (1996) Metabolic Changes in Hypothyroidism. In: Braverman, L.E. and Utiger, R.D., Eds., Werner and Ingbar's the thyroid, 7th Edition, Lippincott Raven, Philadelphia, 858-863.

[6] Duntas, L.H. (2002) Thyroid Disease and Lipids. Thyroid, 12, 287-293. http://dx.doi.org/10.1089/10507250252949405

[7] Rizos, C.V., Elisaf, M.S. and Liberopoulos, E.N. (2011) Effects of Thyroid Dysfunction on Lipid Profile. The Open Cardiovascular Medicine Journal, 5, 76.

[8] Lazar, M.A. (1993) Thyroid Hormone Receptors: Multiple Forms, Multiple Possibilities. Endocrine Reviews, 14, 184193.

[9] Ness, G.C., Dugan, R.E., Lakshmanan, M.R., Nepokroeff, C.M. and Porter, J.W. (1973) Stimulation of Hepatic Hydroxy-Methyl-Glutaryl Coenzyme A Reductase in Hypophysectomized Rats by L-Triiodothyronine. Proceedings of the National Academy of Sciences of the United States of America, 70, 3839-3842. http://dx.doi.org/10.1073/pnas.70.12.3839

[10] Bakker, O., Hudig, F., Meijssen, S. and Wiersinga, W.M. (1998) Effects of Triiodothyronine and Amiodarone on the Promoter of the Human LDL Receptor Gene. Biochemical and Biophysical Research Communications, 249, 517-521. http://dx.doi.org/10.1006/bbrc.1998.9174

[11] Lagrost, L. (1994) Regulation of Cholesteryl Ester Transfer Protein (CETP) Activity: Review of in Vitro and in Vivo Studies. Biochimica et Biophysica Acta (BBA)—Lipids and Lipid Metabolism, 1215, 209-236. http://dx.doi.org/10.1016/0005-2760(94)90047-7

[12] Kuusi, T., Saarinen, P. and Nikkilä, E.A. (1980) Evidence for the Role of Hepatic Endothelial Lipase in the Metabolism of Plasma High Density Lipoprotein2 in Man. Atherosclerosis, 36, 589-593. http://dx.doi.org/10.1016/0021-9150(80)90251-8

[13] Dhanunjaya, Y., Vijaya, D. and Dolia, P.B. (2014) Decreased Basal Activity of HDL Associated Enzyme: Paraoxonase (PON) during Uncompensated Oxidative Stress among Type 2 Diabetes Mellitus Patients. International Journal of Diabetes in Developing Countries, 35, 483-490. http://dx.doi.org/10.1007/s13410-014-0218-7

[14] Navab, M., Reddy, S.T., Van Lenten, B.J., Buga, G.M., Ananthramaith, G.M. and Fogelman, A.M. (2007) HDL and Inflammation. In: Fielding, C.J., Ed., High density Lipoprotein, from Basic Biology to Clinical Aspects, Wiley-VCH Verlag GmbH \& Co., Weinheim, 341. http://dx.doi.org/10.1002/9783527625178.ch13

[15] Gavish, D., Oschry, Y. and Eisenberg, S. (1987) In Vivo Conversion of Human HDL3 to HDL2 and ApoE-Rich HDL1 in the Rat: Effects of Lipid Transfer Protein. Journal of Lipid Research, 28, 257-267.

[16] Santamarina-Fojo, S., González-Navarro, H., Freeman, L., Wagner, E. and Nong, Z. (2004) Hepatic Lipase, Lipoprotein Metabolism, and Atherogenesis. Arteriosclerosis, Thrombosis, and Vascular Biology, 24, 1750-1754. http://dx.doi.org/10.1161/01.ATV.0000140818.00570.2d

[17] Larsen, P.R., Davies, T.F. and Hay, I.D. (1998) The Thyroid Gland. In: Wilson, J.D., Foster, D.W., Kronenberg, H.M. and Larsen, P.R., Eds., Williams Textbook of Endocrinology, 9th Edition, W. B. Saunders Co., Philadelphia, 389-515.

[18] Bianco, A.C., Salvatore, D., Gereben, B., Berry, M.J. and Larsen, P.R. (2002) Biochemistry, Cellular and Molecular Biology, and Physiological Roles of the Iodothyronine Selenodeiodinases. Endocrine Reviews, 23, 38-89. http://dx.doi.org/10.1210/edrv.23.1.0455

[19] Larsen, P.R., Silva, J.E. and Kaplan, M.M. (1981) Relationships between Circulating and Intracellular Thyroid Hor- 
mones: Physiological and Clinical Implications. Endocrine Reviews, 2, 87-102. http://dx.doi.org/10.1210/edrv-2-1-87

[20] Dora, J.M., Machado, W.E., Rheinheimer, J., Crispim, D. and Maia, A.L. (2010) Association of the Type 2 Deiodinase Thr92Ala Polymorphism with Type 2 Diabetes: Case-Control Study and Meta-Analysis. European Journal of Endocrinology, 163, 427-434. http://dx.doi.org/10.1530/EJE-10-0419

[21] Canani, L.H., Capp, C., Dora, J.M., Meyer, E.L.S., Wagner, M.S., Harney, J.W., et al. (2005) The Type 2 Deiodinase A/G (Thr92Ala) Polymorphism Is Associated with Decreased Enzyme Velocity and Increased Insulin Resistance in Patients with Type 2 Diabetes Mellitus. The Journal of Clinical Endocrinology \& Metabolism, 90, 3472-3478. http://dx.doi.org/10.1210/jc.2004-1977

[22] Steinsapir, J., Bianco, A.C., Buettner, C., Harney, J. and Larsen, P.R. (2000) Substrate-Induced Down-Regulation of Human Type 2 Deiodinase (hD2) Is Mediated through Proteasomal Degradation and Requires Interaction with the Enzyme’s Active Center. Endocrinology, 141, 1127-1135. http://dx.doi.org/10.1210/en.141.3.1127 http://dx.doi.org/10.1210/endo.141.3.7355

[23] Mentuccia, D., Proietti-Pannunzi, L., Tanner, K., Bacci, V., Pollin, T.I., Poehlman, E.T., et al. (2002) Association between a Novel Variant of the Human Type 2 Deiodinase Gene Thr92Ala and Insulin Resistance Evidence of Interaction with the Trp64Arg Variant of the $\beta$-3-Adrenergic Receptor. Diabetes, 51, 880-883. http://dx.doi.org/10.2337/diabetes.51.3.880

[24] Kilic, S.S., Aydin, S., Kilic, N., Erman, F., Aydin, S. and Celik, İ. (2005) Serum Arylesterase and Paraoxonase Activity in Patients with Chronic Hepatitis. World Journal of Gastroenterology, 11, 7351-7354. http://dx.doi.org/10.3748/wjg.v11.i46.7351

[25] Draper, H.H. and Hadley, M. (1990) Malondialdehyde Determination as Index of Lipid Peroxidation. Methods in Enzymology, 186, 421-431. http://dx.doi.org/10.1016/0076-6879(90)86135-I

[26] Marklund, S. and Marklund, G. (1974) Involvement of the Superoxide Anion Radical in the Autoxidation of Pyrogallol and a Convenient Assay for Superoxide Dismutase. European Journal of Biochemistry, 47, 469-474. http://dx.doi.org/10.1111/j.1432-1033.1974.tb03714.x

[27] Ye, S., Humphries, S. and Green, F. (1992) Allele Specific Amplification by Tetra-Primer PCR. Nucleic Acids Research, 20, 1152. http://dx.doi.org/10.1093/nar/20.5.1152

[28] Wu, P. (2000) Thyroid Disease and Diabetes. Clinical Diabetes, 18, 38-39.

[29] Panicker, V., Saravanan, P., Vaidya, B., Evans, J., Hattersley, A.T., Frayling, T.M. and Dayan, C.M. (2009) Common Variation in the DIO2 Gene Predicts Baseline Psychological Well-Being and Response to Combination Thyroxine plus Triiodothyronine Therapy in Hypothyroid Patients. The Journal of Clinical Endocrinology \& Metabolism, 94, 16231629. http://dx.doi.org/10.1210/jc.2008-1301

[30] Meulenbelt, I., Min, J.L., Bos, S., Riyazi, N., Houwing-Duistermaat, J.J., van der Wijk, H.J., et al. (2008) Identification of DIO2 as a New Susceptibility Locus for Symptomatic Osteoarthritis. Human Molecular Genetics, 17, 1867-1875. http://dx.doi.org/10.1093/hmg/ddn082

[31] Gumieniak, O., Perlstein, T.S., Williams, J.S., Hopkins, P.N., Brown, N.J., Raby, B.A. and Williams, G.H. (2007) Ala92 Type 2 Deiodinase Allele Increases Risk for the Development of Hypertension. Hypertension, 49, 461-466. http://dx.doi.org/10.1161/01.HYP.0000256295.72185.fd

[32] Alina, B., Daria, P., Olga, F., Vladislav, S., Anna, K. and Elena, G. (2012) Thr92Ala Polymorphism of Human Type 2 Deiodinase Gene (hDIO2) Affects the Development of Graves’ Disease, Treatment Efficiency, and Rate of Remission. Clinical and Developmental Immunology, 2012, Article ID: 340542. http://dx.doi.org/10.1155/2012/340542

[33] Guo, T.W., Zhang, F.C., Yang, M.S., Gao, X.C., Bian, L., Duan, S.W., et al. (2004) Positive Association of the DIO2 (Deiodinase Type 2) Gene with Mental Retardation in the Iodine-Deficient Areas of China. Journal of Medical Genetics, 41, 585-590. http://dx.doi.org/10.1136/jmg.2004.019190

[34] Schneider, M.J., Fiering, S.N., Pallud, S.E., Parlow, A.F., St. Germain, D.L. and Galton, V.A. (2001) Targeted Disruption of the Type 2 Selenodeiodinase Gene (DIO2) Results in a Phenotype of Pituitary Resistance to T4. Molecular Endocrinology, 15, 2137-2148. http://dx.doi.org/10.1210/mend.15.12.0740

[35] Camont, L., Chapman, M.J. and Kontush, A. (2011) Biological Activities of HDL Subpopulations and Their Relevance to Cardiovascular Disease. Trends in Molecular Medicine, 17, 594-603. http://dx.doi.org/10.1016/j.molmed.2011.05.013

[36] Tan, K.C.B., Shiu, S.W.M. and Kung, A.W.C. (1998) Effect of Thyroid Dysfunction on High-Density Lipoprotein Subfraction Metabolism: Roles of Hepatic Lipase and Cholesteryl Ester Transfer Protein. The Journal of Clinical Endocrinology \& Metabolism, 83, 2921-2924. http://dx.doi.org/10.1210/jc.83.8.2921 http://dx.doi.org/10.1210/jcem.83.8.4938

[37] Ezaki, O. (1997) Regulatory Elements in the Insulin-Responsive Glucose Transporter (GLUT4) Gene. Biochemical and Biophysical Research Communications, 241, 1-6. http://dx.doi.org/10.1006/bbrc.1997.7587 